from irregularly oscillating waterbeds appears to reduce apnoea, ${ }^{6}$ although regularly oscillating waterbeds may be less effective. ${ }^{7}$ Documented hazards of waterbeds include hypothermia, and the risk of accidental puncture. The rocking bed avoids these, and although there might have been problems with vomiting, no baby vomited during the study, nor has any done so in ordinary clinical use.

In this preliminary study, rocking appeared to diminish the frequency of apnoeic attacks, including those associated with hypoxia, and to reduce the need for active intervention to re-establish respiration. Bradycardia without cessation of movements on the impedance pneumogram (which may sometimes have been due to obstructive apnoea) was also less common. The rocking bed may prove helpful in the management of recurrent apnoea of prematurity.

\footnotetext{
References

1 Speidel B D, Dunn P M. Use of nasal continuous positive airway pressure to treat severe recurrent apnoea in very preterm infants. Lancet 1976; ii: 658-60.

2 Kuzemko J A, Paala J. Apnoeic attacks in the newborn treated with aminophylline. Arch Dis Child 1973; 48: 404-6.
}

3 Haas R H, Davies P A. Iatrogenic hazards in the newborn intensive care unit. In: Wharton B A, ed. Topics in perinatal medicine. Tunbridge Wells: Pitman Medical, 1980: 104-19.

4 Shapiro D L. Comments on the use of theophylline for apnea in premature infants. In: Lucey J F, Shannon D C, Soyka L F, eds. Apnea of prematurity. Report of the seventy-first Ross Conference on Pediatric Research. Columbus, Ohio: Ross Laboratories, 1977: 67-70.

5 Kattwinkel J, Nearman H S, Fanaroff A A, Katona P G, Klaus M H. Apnea of prematurity. Comparative therapeutic effects of cutaneous stimulation and nasal continuous positive airway pressure. $J$ Pediatr 1975; 86: 588-92.

- Korner A F, Guilleminault C, Van den Hoed J, Baldwin R B. Reduction of sleep apnea and bradycardia in preterm infants on oscillating waterbeds: a controlled polygraphic study. Pediatrics 1978 ; 61 : 528-33.

7 Jones R A K. A controlled trial of a regularly cycled oscillating waterbed and a non-oscillating waterbed in the prevention of apnoea in the preterm infant. Arch Dis Child 1981; 56: 889-91.

Correspondence to Dr S J Tuck, Jenny Lind Children's Department, Norfolk and Norwich Hospital, Brunswick Road, Norwich NR1 3SR.

Received 1 February 1982

\title{
Percutaneous alcohol absorption and skin necrosis in a preterm infant
}

\author{
V HARPIN AND N RUTTER \\ Department of Neonatal Medicine and Surgery, City Hospital, Hucknall Road, Nottingham
}

SUMMARY A 27-week gestation infant developed severe haemorrhagic skin necrosis on the back and buttocks after umbilical arterial catheterisation. Before catheterisation the skin was cleaned with methylated spirits. A blood alcohol level taken 18 hours after catheterisation showed a blood ethanol level of $259 \mathrm{mg} / 100 \mathrm{ml}$ and a blood methanol level of $26 \mathrm{mg} / 100 \mathrm{ml}$. We conclude that the methylated spirits caused this extensive skin damage and that percutaneous absorption via the readily permeable skin of this immature baby resulted in the dangerously high alcohol levels.

The keratinised stratum corneum which gives adult skin its barrier properties, begins to develop in the seventh month of fetal life. The thin poorly keratinised skin of a preterm baby is therefore an ineffective barrier and percutaneous absorption of toxic compounds-such as aniline dyes ${ }^{1}$ and hexachlorophane ${ }^{2}$-has been well documented. Damage to the skin itself has been reported in association with umbilical arterial catheterisation. It has been suggested that this might be due to vascular obstruction ${ }^{3}$ or to local toxic effects of cleansing solutions ${ }^{4}$ used to prepare the skin before catheterisation. We report a very immature baby who was shown to have dangerously high blood alcohol levels after skin cleansing with methylated spirits and who developed extensive skin damage of the type previously reported.

\section{Case report}

Twenty-seven week gestation twins were born to a healthy, 26-year-old mother who had had one previous normal pregnancy. The membranes had ruptured at 22 weeks' gestation.

Twin 1. The first, a boy weighing $865 \mathrm{~g}$, was born by difficult breech delivery. Pulsation of the cord ceased sometime before delivery. The baby was asphyxiated at birth and did not respond to resuscitation. He died aged 2 hours 20 minutes. 
Twin 2. The second, a girl weighing $985 \mathrm{~g}$, was also born by breech delivery but needed no resuscitation. Soon after birth she began to develop signs of respiratory distress. At age 1 hour a 4 FG umbilical arterial catheter (Searle Life Support Systems, High Wycombe, Buckinghamshire) was inserted. The baby's skin was cleaned with industrial methylated spirits. The procedure was prolonged but a catheter was eventually inserted successfully and an $x$-ray film showed the tip to be about $1.5 \mathrm{~cm}$ above the diaphragm. At 6 hours the baby needed $40 \%$ oxygen and was having frequent apnoeic episodes. In view of the prolonged rupture of membranes an infection screen was performed and intravenous penicillin, gentamicin, and aminophylline were started. The infection screen included a lumbar puncture for which further skin cleaning with methylated spirits was required. At this time skin lesions were noted in the right lumbar region and the arterial line was removed because of possible ischaemia. At age 12 hours the baby was intubated and started on $4 \mathrm{~cm}$ continuous positive airways pressure (CPAP). By this time the haemorrhagic skin lesions had extended to both lumbar regions and buttocks. The plum coloured, damaged area had a distinct edge (Figure) and one small central region broke down leaving a raw area. The legs and feet were bruised as a result of the delivery but developed no further lesions. At age 21 hours intermittent positive pressure ventilation (IPPV) was begun for apnoea. At 48 hours the baby, who had been stable for some hours on the ventilator, suddenly collapsed. The electrocardiogram monitor showed ventricular fibrillation. Resuscitation was unsuccessful. In view of the gross haemorrhagic skin

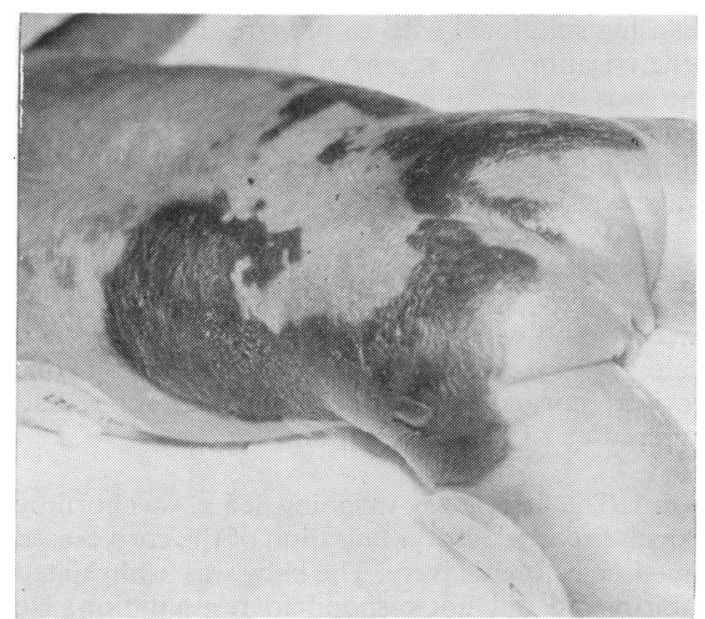

Figure The baby aged about 20 hours. lesions a blood alcohol level was measured at age 19 hours (gas liquid chromatography). The blood ethanol level was $259 \mathrm{mg} / 100 \mathrm{ml}$ and the blood methanol level $26 \mathrm{mg} / 100 \mathrm{ml}$. No ethanol or methanol was used to clean the skin before sampling. A blood sample at necropsy showed levels of 64 $\mathrm{mg} / 100 \mathrm{ml}$ (ethanol) and $6 \mathrm{mg} / 100 \mathrm{ml}$ (methanol). A post-mortem sample on the first twin contained no detectable alcohol. Regular Dextrostix and a blood glucose analysis were normal and there was no severe metabolic acidosis (lowest arterial pH 7.15). Post-mortem examination showed a fresh intraventricular haemorrhage. Skin histology showed superficial necrosis with no evidence of vascular damage.

\section{Discussion}

This case illustrates two important points in the care of extremely preterm babies. Firstly, that any substance which comes into contact with the skin of such babies is rapidly absorbed into the blood stream. Secondly, that this delicate skin can easily be damaged. Those most at risk are newborn babies of less than 30 weeks' gestation and less than $1 \mathrm{~kg}$ in weight.

Choosing a suitable antiseptic solution for skin preparation for the many procedures necessary in neonatal intensive care is a particular problem. Hexachlorophane absorption with resulting nervous system damage has been described. ${ }^{5}$ Iodinecontaining skin cleansing solutions have been incriminated in cases of goitre and transient neonatal hypothyroidism. ${ }^{6}$ Studies on chlorhexidine blood levels in babies after bathing in chlorhexidine suggest that only minimal amounts are absorbed but such studies were not made on extremely immature babies most at risk. ${ }^{7}$

Industrial methylated spirits is commonly used. It consists of $95 \%$ ethanol and $5 \%$ wood naptha (which is at least $60 \%$ methanol). A baby of the size of this 27-week gestation twin need only absorb one-third of a millilitre of methylated spirits to reach the dangerous blood levels recorded. We do not know how important alcohol intoxication was in this baby's illness and death but, since the first alcohol level was not taken until 18 hours after the catheterisation, it is likely that the maximum level reached was in the potentially fatal range.

Haemorrhagic skin lesions after umbilical artery catheterisation are well known. ${ }^{3}$ This case gives further support to the theory that such lesions are the result of local skin damage due to cleansing agents. ${ }^{4}$ Histology showed only superficial skin damage and no vascular disturbance. There is sparing of the gluteal crease and the distribution 
is not typical of an area of vascular supply. The alcohol would not be able to evaporate if the baby is lying on it, and the underlying surface would therefore act as an occlusive dressing. The site of the lesions suggests that the cleansing solution drips down to soak the surface on which the baby is lying. Püschel ${ }^{8}$ recently reported a case of percutaneous alcohol intoxication in a 2-year-old child when alcohol-soaked bandages were applied to damaged skin. The child showed features of alcohol intoxication and developed haemorrhagic skin lesions.

The use of alcoholic solutions to clean the skin of immature babies is potentially dangerous. This report is a reminder that great care must be taken if pharmacologically active agents are applied to immature skin.

\footnotetext{
References

1 Kagan B M, Mirman B, Calvin J, Lundeen E. Cyanosis in premature infants due to aniline dye intoxication. J Pediatr 1949; 34: 574-8.
}

2 Curley A, Hawk R E, Kimbrough R D, Nathenson G, Finberg L. Dermal absorption of hexachlorophane in infants. Lancet 1971; ii: 296-7.

3 Mann N P. Gluteal skin necrosis after umbilical artery catheterisation. Arch Dis Child 1980; 55: 815-7.

4 Wilkinson A R, Baum J D, Keeling J W. Letter: Superficial skin necrosis in babies prepared for umbilical arterial catherisation. Arch Dis Child 1981 ; 56: 237-8.

5 Powell H, Swarner O, Gluck L, Lampert P. Hexachlorophene myelinopathy in premature infants. $J$ Pediatr 1973; 82: 976-81.

6 Chabrolle J P, Rossier A. Goitre and hypothyroidism in the newborn after cutaneous absorption of iodine. Arch Dis Child 1978; 53: 495-8.

7 Cowen J, Ellis S H, McAinsh J. Absorption of chlorhexidine from the intact skin of newborn infants. Arch Dis Child 1979; 54: 379-83.

8 Püschel K. Percutaneous alcohol intoxication. Eur $J$ Pediatr 1981 ; 136: 317-8.

Correspondence to Dr N Rutter, Department of Neonatal Medicine and Surgery, City Hospital, Hucknall Road, Nottingham NG5 1PD.

Received 23 February 1982

\section{Debendox does not cause the Poland anomaly}

\author{
T J DAVID \\ Department of Child Health, University of Manchester
}

SUMMARY The suggestion that Debendox may cause the Poland anomaly is refuted by a study of the antenatal drug exposure in 46 cases of the Poland anomaly and 32 cases of isolated absence of the pectoralis major. Debendox had been prescribed in one case of the Poland anomaly and in one case of isolated pectoralis absence, but in neither was the compound given during organogenesis. In none of the 78 cases could Debendox be causally implicated.

The Poland anomaly is a rare congenital malformation comprising unilateral absence of the pectoralis major muscle with an ipsilateral hand defect. Isolated absence of the pectoralis major may be a related malformation, and the two conditions possibly represent a spectrum of defects.

Debendox is an antiemetic drug used in pregnancy. It is a combination of dicyclomine hydrochloride $10 \mathrm{mg}$, doxylamine succinate $10 \mathrm{mg}$, and pyridoxine $10 \mathrm{mg}$. It has been marketed in the UK since 1958. It has been specifically suggested that Debendox may cause the Poland anomaly. ${ }^{12}$ In a recent study of Debendox and limb reduction deformities, ${ }^{3}$ out of 40932 births there were 15 cases of limb reduction deformities. In only 3 was there a history of first trimester Debendox exposure, but in 2 of them the limb reduction deformity was the Poland anomaly. In the remaining 12 cases of limb reduction defects without first trimester exposure to Debendox there were no cases of the Poland anomaly.

In view of the specificity of teratogens, notably thalidomide, it was decided to pursue a specific causal relationship between the Poland anomaly, the related defect of isolated pectoralis absence, and the use of Debendox in pregnancy.

\section{Materials and methods}

Since 1970, a study of the aetiology of the Poland anomaly has been in progress. Cases were referred to me by paediatricians and plastic surgeons who know of my interest in it, but were not selected in any way. All cases were seen before it had been suggested $^{1}$ that Debendox might cause the Poland anomaly. A special examination of the mother's antenatal drug exposure was made in each case. The patients comprise two groups (1) 32 cases with isolated pectoralis major absence, and (2) 46 cases with the Poland anomaly. All cases were examined 